\section{A case of atypical systemic pri- mary carnitine deficiency in Saudi Arabia}

\author{
Abdulrahman Alghamdi, 1,2 \\ Hani Almalki, 1,2 Aiman Shawli, ${ }^{1-3}$ \\ Rahaf Waggass, 1,2,4 Fahad Hakami1,2,5 \\ 1King Abdullah International Medical \\ Research Center; ${ }^{2}$ King Saud bin \\ Abdulaziz University for Health \\ Sciences; ${ }^{3}$ Department of Pediatrics; \\ ${ }^{4}$ King Faisal Cardiac Center; \\ 5 Molecular Medicine Section, \\ Department of Pathology and \\ Laboratory Medicine, King Abdulaziz \\ Medical City-WR, Jeddah, Saudi Arabia
}

\begin{abstract}
Systemic primary carnitine deficiency (SPCD) is an autosomal recessive inborn error of fatty acid metabolism caused by a defect in the transporter responsible for moving carnitine across plasma membrane. The clinical features of SPCD vary widely based on the age of onset and organs involved. During infancy, patients might show episodes of hypoketotic hypoglycemia, hepatomegaly, elevated transaminases, and hyperammonemia. Skeletal myopathy, elevated creatine kinase, and cardiomyopathy are the main manifestations in children with SPCD, while in adults, the disorder is usually manifested as cardiomyopathy, arrhythmias, or fatigability. Here, we report a 5-year-old boy with SPCD that presented as dilated cardiomyopathy with atypical features, such as anemia, respiratory distress, and proximal muscle weakness. This report supports considering carnitine deficiency treatment in the work-up of unexplained pediatric dilated cardiomyopathy.
\end{abstract}

\section{Introduction}

Carnitine is a hydrophilic amino acid that is naturally produced in the brain, liver and kidney from two essential amino acids, lysine and methionine, although $75 \%$ of carnitine is actually obtained from dairy products.1,2 Carnitine is a major player in mitochondrial oxidation of long-chain fatty acids and overall energy metabolism. ${ }^{3} \mathrm{Bi}$ allelic mutations in the SLC22A5 gene, which encodes the organic cation/carnitine transporter 2 (OCTN2) protein, cause systemic primary carnitine deficiency (SPCD).
OCTN2 moves carnitine across the plasma membrane, and is widely expressed in the plasma membrane of the myocardium, skeletal muscle, renal tubules, fibroblast, intestine and placental cells. ${ }^{4}$ Impaired OCTN2 protein restricts tissue uptake, leading to decreased intracellular carnitine accumulation in the heart and skeletal muscle and increases renal carnitine loss, and subsequently systemic carnitine depletion. ${ }^{5-}$ 7 In addition, a deficiency of carnitine results in an inability to utilize fat leading to hypoglycemia and the accumulation of fats in the liver, muscle, and heart, which could eventually lead to hepatic steatosis, hepatomegaly, myopathy and dilated cardiomyopathy (DCM). ${ }^{8}$ Genetic deficiencies of OCTN2 transporter activity represent the only known forms of the SPCD, which is also known as carnitine uptake defect or carnitine transporter deficiency. SPCD is an autosomal recessive disorder that encompasses a broad range of clinical manifestations in relation to the age of onset, severity, and the organ involved. Affected infants present with metabolic decompensation symptoms, such as poor feeding, irritability, lethargy, and hepatomegaly. The myopathic presentation in children aged between two and four years is characterized by DCM, hypotonia, skeletal muscles weakness, and elevated serum creatine kinase levels. ${ }^{9}$ Other atypical symptoms that have been reported in only a few cases are anemia, 10 proximal muscle weakness, global developmental delay, ${ }^{11}$ respiratory distress, ${ }^{12}$ and arrhythmias. ${ }^{13}$ Early diagnosis and treatment with oral L-carnitine (100-400 $\mathrm{mg} / \mathrm{kg} /$ day) prevents metabolic decompensation and improves skeletal and cardiac muscle function. ${ }^{9}$

The worldwide incidence of SPCD is estimated to be $1: 100,000$, with the highest incidence reported in Japan (approximately 1:40,000 newborns). ${ }^{14}$ In a retrospective study of the incidence of inborn errors of metabolism in the Eastern Province conducted over a 25-year period (1983-2008), only two unrelated infants out of 165,530 Saudi newborns were diagnosed with SPCD. ${ }^{15}$ In a similar study conducted in a tertiary structure in the Central Province, only one out of 110,601 Saudi newborns was diagnosed with SPCD. ${ }^{16}$ Therefore, it can be speculated that the incidence of SPCD in Saudi Arabia is similar to the international incidence. To date, only seven SPCD cases have been reported in Saudi Arabia. ${ }^{15-19}$

In this report, we present a case of a five-year-old SPCD patient with DCM and atypical manifestations including history of anemia, frequent respiratory distress and proximal muscle weakness. Genetic analy-
Correspondence: Fahad Hakami, Molecular Medicine Section, Department of Pathology and Laboratory Medicine, King Abdulaziz Medical City-WR, P.O. Box 9515, 21423 Jeddah, Saudi Arabia.

Tel.: +966.0.122262828.

E-mail: HakamiFM@ngha.med.sa

Key words: Systemic Primary Carnitine Deficiency, SLC22A5, Dilated Cardiomyopathy, OCTN2.

Contributions: the authors contributed equally.

Conflict of interest: the authors declare no potential conflict of interest.

Funding: none.

Further information: informed consent for publication was obtained from the patient's father.

Received for publication: 9 April 2018. Accepted for publication: 24 June 2018

This work is licensed under a Creative Commons Attribution NonCommercial 4.0 License (CC BY-NC 4.0).

(C) Copyright A. Alghamdi et al., 2018

Licensee PAGEPress, Italy

Pediatric Reports 2018; 10:7705

doi:10.4081/pr.2018.7705

sis revealed a homozygous missense pathogenic variant in the SLC22A5 gene, which was consistent with SPCD clinical picture.

\section{Case Report}

A five-year-old boy, a son of Saudi consanguineous parents, was referred to King Abdulaziz Medical City-Western Region (KAMC-WR) with DCM, hepatomegaly, history of anemia and progressive proximal muscle weakness. The patient had a history of frequent respiratory distress started in the early months of his life, and had been previously admitted to a primary medical center multiple times for oxygen supplementation. He was thought to suffer from hyperactive airways. The patient was described by his family to be constantly irritable and fatigue with poor feeding. The parents had a history of three spontaneous abortions and death of twins (male and female) on their first and second day of life, respectively (Figure 1A). At time of diagnosis, the patient's electrocardiogram (ECG) showed a peaked Twave pattern and left ventricular hypertrophy (Figure 2). Echocardiography examinations also showed reduced ejection fracture $(\mathrm{EF}=49 \%)$, reduced shortening fraction 
( $F S=25 \%$ ), and left ventricular end diastolic (LVED) dimension of $5.09 \mathrm{~cm}$, indicating DCM (Table 1 and Figure 3A). The patient was placed on furosemide, captopril and digoxin medications. Laboratory work-up results showed borderline-to-low hemoglobin $(10 \mathrm{gm} / \mathrm{dL}$, reference range for patient's age: $11-14.5 \mathrm{~g} / \mathrm{dL}$ ), borderline-to-low mean corpuscular volume $(73.9 \mathrm{fL}$, reference range for patient's age: $75-89 \mathrm{fL})$, low total carnitine level $(16.3 \mu \mathrm{mol} / \mathrm{L}$, reference range for patient's age: $35-90 \mu \mathrm{mol} / \mathrm{L}$ ), low free carnitine level $(8.8 \mu \mathrm{mol} / \mathrm{L}$, reference range for patient's age: $25-55 \mu \mathrm{mol} / \mathrm{L})$, and acylcarnitine/ free carnitine ratio of 0.9 (reference range for patient's age: 0.1-0.8). Based on these values and the clinical manifestations, SPCD was suspected; however, the presence of anemia, respiratory distress, and proximal muscle weakness complicated the diagnosis to some extent and made it necessary to confirm the diagnosis by genetic testing.

Whole exome sequencing (WES) performed for our patient identified a homozygous missense pathogenic variant in the SLC22A5 gene (c.1409C $>$ T; p.Ser470Phe). An unrelated Saudi patient with SPCD has been previously reported to be homozygous for this variant. ${ }^{17,20}$ In addition, this variant was identified in two of 246,236 chromosomes of South Asian origin by The Genome Aggregation Database (http://gnomad.broadinstitute.org/; dbSNP rs386134222). In-vitro studies showed that the biochemical consequence of this variant was a marked reduction in fibroblast carnitine uptake to $7.1 \%$ of normal controls. ${ }^{20}$ Based on the overall data and genotypephenotype correlation, the identified variant was considered to be disease-causing in this family and confirmed SPCD in our patient.

Following genetic confirmation, furosemide, captopril and digoxin were tapered gradually and the patient was started on L-carnitine $500 \mathrm{mg}$ TID (100 $\mathrm{mg} / \mathrm{kg} /$ day). The treatment response was assessed regularly by monitoring clinical symptoms, ECG and measuring plasma levels of total and free carnitine. After one month of carnitine supplementation, the patient showed a significant improvement in symptoms and became active. Repeated echocardiography showed normal cardiac function with mild dilation of the left ventricle $(\mathrm{EF}=72 \%, \mathrm{FS}=40 \%$, LVED dimension $3.85 \mathrm{~cm}$, and Z-score=1.8; Table 1 and Figure 3B). After 14 months of L-carnitine supplementation, total carnitine was increased to $35.1 \mu \mathrm{mol} / \mathrm{L}$ (reference range for patient's age: $35-90 \mu \mathrm{mol} / \mathrm{L})$, plasma levels of free carnitine reached $16.3 \mu \mathrm{mol} / \mathrm{L}$ (reference range for patient's age: 25-55 $\mu \mathrm{mol} / \mathrm{L}$ ), and the acylcarnitine/free carni- tine ratio was 1.2 (reference range for patient's age: 0.1-0.8). Other features, such as anemia and respiratory distress, disappeared with continuous carnitine supplementation.

\section{Discussion and Conclusions}

This case report illustrates an example of the variation in the presentation of SPCD with typical and atypical features, and demonstrates the power of genetic testing in

A

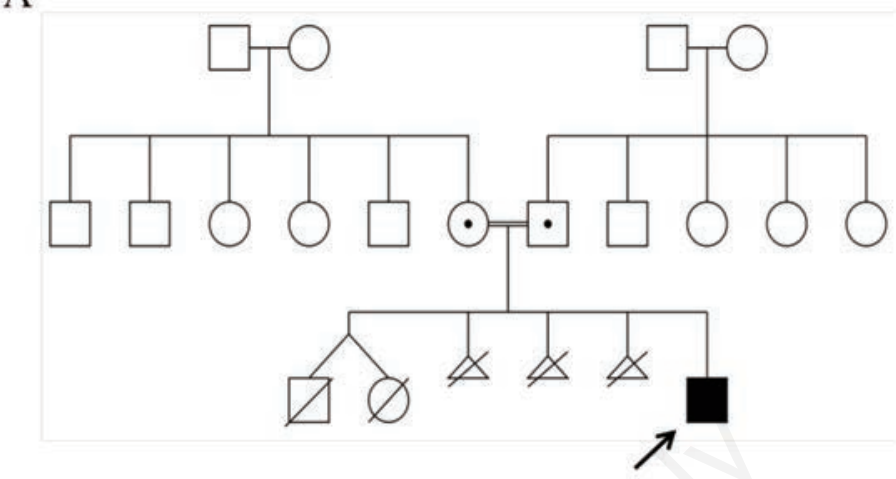

B

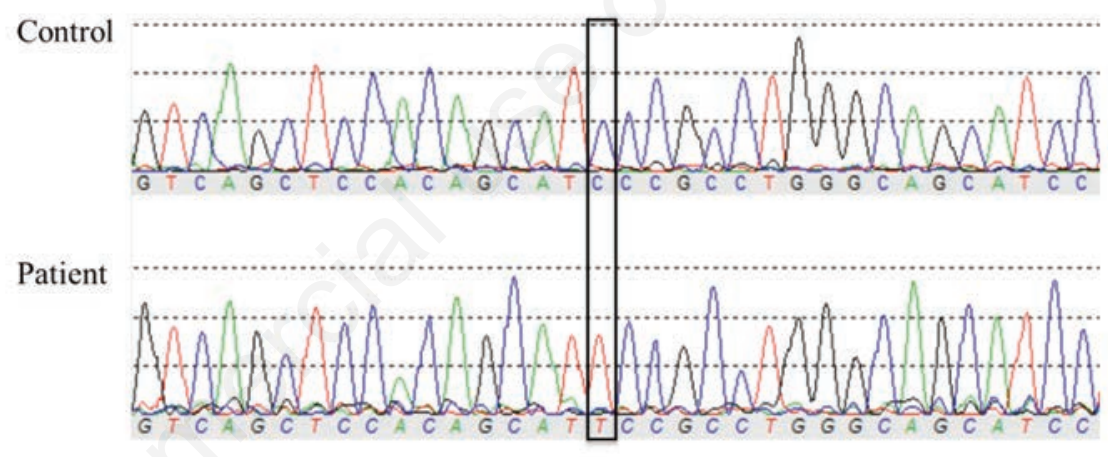

Figure 1. (A) Pedigree of the affected family and (B) representative chromograph of SLC22A5 Sanger sequencing read. Black rectangle indicates the affected nucleotide; c.1409C >T (NM_003060.3).

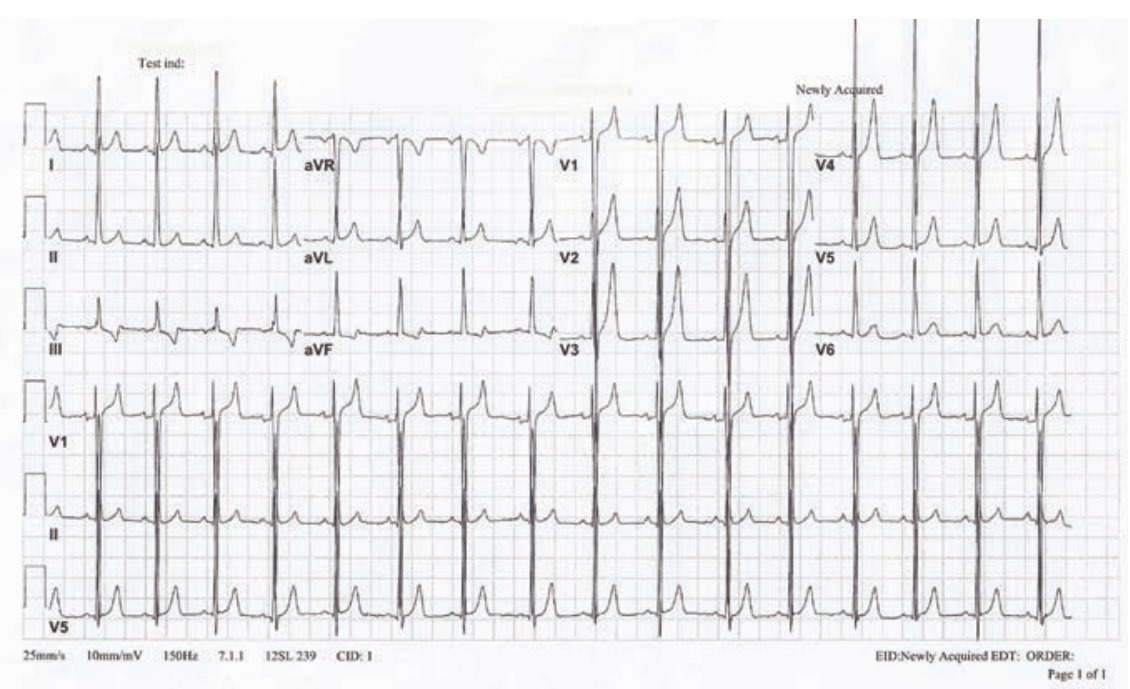

Figure 2. Electrocardiogram at the time of diagnosis showing features of carnitine deficiency cardiomyopathy. Note the peaked T-wave along with the short QT interval. 
Table 1. Echocardiography findings of 5-year-old boy with systemic primary carnitine deficiency.

\begin{tabular}{lllll} 
Parameter & At diagnosis & $\begin{array}{l}\text { Before starting L-carnitine } \\
\text { supplements }\end{array}$ & $\begin{array}{l}\text { One month post-L-carnitine } \\
\text { supplementation }\end{array}$ & $\begin{array}{c}\text { Six months post-L-carnitine } \\
\text { supplementation }\end{array}$ \\
$\begin{array}{llll}\text { Ejection fraction } \\
\text { Shortening fraction }\end{array}$ & $49 \%$ & $40.9 \%$ & $64.6 \%$ & $72 \%$ \\
\hline $\begin{array}{l}\text { Left ventricular end } \\
\text { diastolic dimension }\end{array}$ & $4.80 \mathrm{~cm}$ & $21 \%$ & $35 \%$ & $40 \%$ \\
Z-score & $6.90 \mathrm{~cm}$ & $4.39 \mathrm{~cm}$ & $3.85 \mathrm{~cm}$ \\
\end{tabular}

confirming the diagnosis. SPCD has a wide range of clinical manifestations that vary based on age of onset and the organ involved. Infantile metabolic presentation, such as in the case of our patient, typically triggered by upper respiratory infection, gastroenteritis or prolonged fasting, and usually start between the ages of three months to two years. This form of SPCD is associated with hepatomegaly, elevated liver enzymes, poor feeding, lethargy, hypoglycemia, minimal ketones in the urine and hyperammonemia. Between the age of two and four years, cardiac and myopathic presentations predominate. Our patient has had the early metabolic decompensation presentations and then developed dilated cardiomyopathy along with three atypical features comprising a history of anemia, frequent respiratory distress and proximal muscle weakness. These atypical manifestations have been previously reported in few individuals with SPCD. ${ }^{10-13}$

Genetic testing, represented here by WES, provides a systematic and unbiased diagnostic tool and provides an efficient route to the identification of the underlying cause of a disease. Although the measurement of plasma carnitine levels is the key to suspect SPCD, genetic testing is needed when the patient's clinical features are atypical. It helps differentiating primary carnitine deficiency from many other causes of carnitine deficiency, such as some organic acidemias, defects of fatty acid oxidation, defects of the carnitine cycle, ${ }^{8}$ and generalized renal tubular dysfunction including renal Fanconi syndrome. ${ }^{21}$ In fact, at least 15 syndromes have been reported to have carnitine deficiency secondary to genetic defects of intermediary metabolism or to other conditions. ${ }^{2,8}$

WES performed for our patient identified the c.1409C $>$ T (p.Ser470Phe) missense pathogenic variant in the SLC22A5 gene. It was suggested that nonsense and frameshift variants in SLC22A5 associate with low carnitine transport activity and a more symptomatic status, while missense mutations cause partial carnitine transport activity and less severe symptoms. ${ }^{22}$ However, a differ-

A

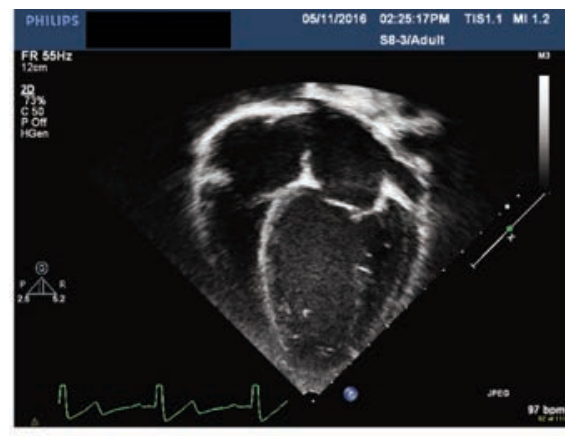

B

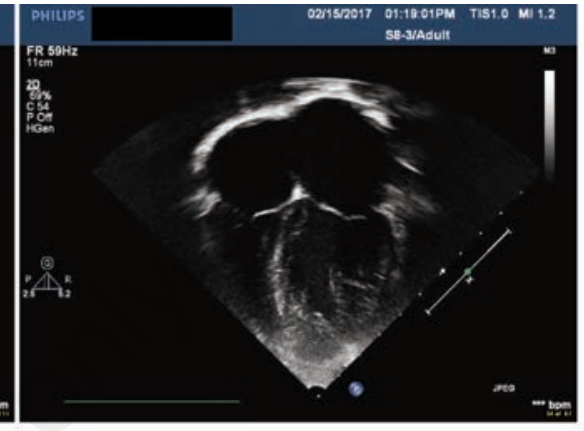

Figure 3. Echocardiography at the time of diagnosis and after treatment with L-carnitine. (A) Transthoracic echocardiography section showing dilated left ventricle at the time of diagnosis; (B) Transthoracic echocardiography section showing normal left ventricular dimensions 6 months following L-carnitine supplementation.

ent report suggests a lack of genotype-phenotype correlation. ${ }^{20}$ The same variant identified in our patient has been previously reported in an Asian child of consanguineous parents who presented at the age of 27 months, earlier than our patient, with hypoglycemic encephalopathy and dilated cardiomyopathy. ${ }^{17,20}$ All of this patient's symptoms were improved and reversed by administration of L-carnitine supplements. Similarly, clinical improvements were seen in our patient, though carnitine analytes were only improved but not completely normalized by L-carnitine supplementation. However, complete normalization of free carnitine levels, which is considered to be a slow and even rare event, has not yet been achieved. ${ }^{23}$ Enhancement of cardiac function was probably the most important clinical improvement. This supports previous suggestion of considering immediate administration of L-carnitine supplements in the work-up of unexplained pediatric DCM. $4,24,25$

SPCD has a favorable prognosis with early diagnosis and L-carnitine supplementation, which must be continued for life. Long-term follow-up reports for patients on L-carnitine supplementation are limited in literature. Thirty years was the longest duration of SPCD follow-up reported, and it was for two siblings with SPCD and hypertrophic cardiomyopathy on L-carnitine supplementation. ${ }^{26}$ Another reported case was followed-up for 28 years. ${ }^{27}$ Those patients had almost normal life with normal heart size on chest X-ray, normal ECG and unremarkable echocardiograms, which demonstrate sustained efficacy of L-carnitine supplementation.

Saudi Arabia has one the highest rates of consanguineous marriages and a prevalence that reaches 58\%. ${ }^{28}$ Therefore, Saudi population is at increased risk for autosomal recessive diseases, particularly inborn errors of metabolism (IEMs). SPCD can be suspected in infants by expanded newborn screening (NBS) using tandem mass spectrometry by detection of low levels of free carnitine (C0). The expanded NBS, which has been established in Saudi Arabia since 2005,29 would provide invaluable chance for early detection and intervention to prevent the progression and fatal complications of IEMs. However, since carnitine can be supplemented through placenta to fetus, the sensitivity of NBS is strongly influenced by maternal $\mathrm{C} 0$ levels, resulting in only half of fetuses with SPCD being detected. 30 This might explain why our patient was not picked up by NBS. 
Med 2001;3:387-92

\section{References}

1. De Vivo D, Tein I. Primary and secondary disorders of carnitine metabolism. Int Pediatr 1990;5:134-41.

2. Flanagan JL, Simmons PA, Vehige J, et al. Role of carnitine in disease. Nutr Metab 2010;7:30.

3. Hoppel C. The role of carnitine in normal and altered fatty acid metabolism. Am J Kidney Dis 2003;41:S4-12.

4. Fu L, Huang M, Chen S. Primary carnitine deficiency and cardiomyopathy. Korean Circ J 2013;43:785-92.

5. Burwinkel B, Kreuder J, Schweitzer S, et al. Carnitine transporter OCTN2 mutations in systemic primary carnitine deficiency: a novel Arg169Gln mutation and a recurrent $\operatorname{Arg} 282$ ter mutation associated with an unconventional splicing abnormality. Biochem Biophys Res Commun 1999;261:484-7.

6. Wang Y, Ye J, Ganapathy V, Longo N. Mutations in the organic cation/carnitine transporter OCTN2 in primary carnitine deficiency. Proceed Natl Acad Sci 1999;96:2356-60.

7. Reuter SE, Faull RJ, Evans AM. L-carnitine supplementation in the dialysis population: Are Australian patients missing out? Nephrology 2008;13:3-16.

8. Longo N, Amat di San Filippo C, Pasquali M. Disorders of carnitine transport and the carnitine cycle. Wiley Online Library: Am J Med Genet Part C: Seminars in Medical Genetics; 2006.

9. Magoulas PL, El-Hattab AW. Systemic primary carnitine deficiency: an overview of clinical manifestations, diagnosis, and management. Orphanet J Rare Dis 2012;7:68.

10. Cano A, Ovaert C, Vianey-Saban C, Chabrol B. Carnitine membrane transporter deficiency: a rare treatable cause of cardiomyopathy and anemia. Pediatr Cardiol 2008;29:163-5.

11. Wang Y, Korman SH, Ye J, et al. Phenotype and genotype variation in primary carnitine deficiency. Genet
12. Erguven M, Yilmaz O, Koc S, et al. A case of early diagnosed carnitine deficiency presenting with respiratory symptoms. Ann Nutr Metab 2007;51:331-4.

13. De Biase I, Champaigne NL, Schroer R, et al. Primary carnitine deficiency presents atypically with long QT syndrome: a case report. JIMD Rep 2012;2:87-90.

14. Koizumi A, Nozaki J-i, Ohura T, et al. Genetic epidemiology of the carnitine transporter OCTN2 gene in a Japanese population and phenotypic characterization in Japanese pedigrees with primary systemic carnitine deficiency. Hum Mol Genet 1999;8:2247-54.

15. Moammar H, Cheriyan G, Mathew R, Al-Sannaa N. Incidence and patterns of inborn errors of metabolism in the Eastern Province of Saudi Arabia, 1983-2008. Ann Saudi Med 2010;30: 271.

16. Alfadhel M, Benmeakel M, Hossain MA, et al. Thirteen year retrospective review of the spectrum of inborn errors of metabolism presenting in a tertiary center in Saudi Arabia. Orphanet J Rare Dis 2016;11:126.

17. Lamhonwah A-M, Onizuka R, Olpin S, et al. OCTN2 mutation (R254X) found in Saudi Arabian kindred: Recurrent mutation or ancient founder mutation? J Inherit Metab Dis 2004;27:473-6.

18. Rahbeeni Z, Vaz F, Al-Hussein K, et al. Identification of two novel mutations in OCTN2 from two Saudi patients with systemic carnitine deficiency. J Inherit Metab Dis 2002;25:363-9.

19. Alrifai MT, AlShaya MA, Abulaban A, Alfadhel M. Hereditary neurometabolic causes of infantile spasms in 80 children presenting to a tertiary care center. Pediatr Neurol 2014;51:390-7.

20. Lamhonwah AM, Olpin SE, Pollitt RJ, et al. Novel OCTN2 mutations: no genotype-phenotype correlations: early carnitine therapy prevents cardiomyopathy. Am J Med Genet Part A
2002;111:271-84.

21. Besouw M, Cornelissen E, Cassiman D, et al. Carnitine profile and effect of suppletion in children with renal Fanconi syndrome due to cystinosis. JIMD Rep 2014; 16:25-30.

22. Rose EC, di San Filippo CA, Erlingsson $\mathrm{N}$, et al. Genotype-phenotype correlation in primary carnitine deficiency. Hum Mutat 2012;33:118-23.

23. Lang F. Encyclopedia of molecular mechanisms of disease. Springer Science \& Business Media; 2009.

24. Kothari S, Sharma M. L-carnitine in children with idiopathic dilated cardiomyopathy. Indian Heart J 1998;50 :59-61.

25. Helton E, Darragh R, Francis P, et al. Metabolic aspects of myocardial disease and a role forl-carnitine in the treatment of childhood cardiomyopathy. Pediatrics 2000;105:1260-70.

26. Kishimoto S, Suda K, Yoshimoto H, et al. Thirty-year follow-up of carnitine supplementation in two siblings with hypertrophic cardiomyopathy caused by primary systemic carnitine deficiency. Int J Cardiol 2012;159:e14-e5.

27. Agnetti A, Bitton L, Tchana B, et al. Primary carnitine deficiency dilated cardiomyopathy: 28 years follow-up. Int J Cardiol 2013;162:e34-e5.

28. El Mouzan M, Al Salloum A, Al Herbish A, et al. Consanguinity and major genetic disorders in Saudi children: a community-based cross-sectional study. Ann Saudi Med 2008;28:169.

29. Alfadhel M, Al Othaim A, Al Saif S, et al. Expanded newborn screening program in Saudi Arabia: Incidence of screened disorders. J Paediatr Child Health 2017;53:585-91.

30. Wilcken B, Wiley V, Sim KG, Carpenter K. Carnitine transporter defect diagnosed by newborn screening with electrospray tandem mass spectrometry. J Pediatr 2001;138:5814. 